\title{
Identification of a persistent primitive trigeminal artery following the transposition technique for trigeminal neuralgia: A case report
}

\author{
Naoki Kato MD¹, Toshihide Tanaka MD¹, Hiroki Sakamoto MD¹, Takao Arai MD¹, \\ Yuzuru Hasegawa MD¹, Toshiaki Abe MD²
}

N Kato, T Tanaka, H Sakamoto, T Arai, Y Hasegawa, T Abe. Identification of a persistent primitive trigeminal artery following the transposition technique for trigeminal neuralgia: A case report. Pain Res Manage 2011;16(5):357-359.

A patient who presented with trigeminal neuralgia associated with a persistent primitive trigeminal artery (PPTA) is presented. A 62-year-old woman suffering from right orbital pain was admitted to the hospital. Medical treatment for three months was ineffective, and her neuralgia had deteriorated and gradually spread in the maxillary division. Magnetic resonance imaging demonstrated the flow void signal attached to the right trigeminal nerve. Thus, microvascular decompression was performed. The superior cerebellar artery was the responsible artery, and it was transposed to decompress the trigeminal nerve. After this manoeuvre, an artery was identified running parallel to the trigeminal nerve toward Meckel's cave. The artery, which turned out to be a PPTA, communicated with the basilar artery. The PPTA was carefully observed, and it was found not to be the artery causing the neuralgia because it did not compress the nerve at surgical observation. No additional procedure between the PPTA and the trigeminal nerve was performed. The patient's symptom improved dramatically following surgery, and her postoperative course was uneventful. Postoperative three-dimensional computed tomography showed the PPTA. The findings in the present case suggest that transposition of the responsible artery effectively decompresses the root entry zone and assists in determining whether the PPTA is affecting the trigeminal nerve.

Key Words: Microvascular decompression; Persistent primitive trigeminal artery; Root entry zone; Superior cerebellar artery; Trigeminal neuralgia
La découverte d'une artère primitive persistante du trijumeau après une technique de transposition pour traiter une névralgie faciale : un rapport de cas

Le cas d'un patient ayant une névralgie faciale associée à une artère primitive persistante du trijumeau (APPT) est présenté. Une femme de 62 ans souffrant d'une douleur de l'orbite droite a été hospitalisée. Le traitement médical d'une durée de trois mois n'avait pas été efficace, et la névralgie s'était aggravée et étendue graduellement dans la division maxillaire. L'imagerie par résonance magnétique a démontré l'absence de signal de flux rattaché au nerf trijumeau droit. On a donc procédé à une décompression microvasculaire. La responsable était l'artère cérébelleuse supérieure, qui a été transposée pour décomprimer le nerf trijumeau. Après cette manœuvre, les médecins ont découvert une artère en parallèle au nerf trijumeau, courant vers la cavité de Meckel.Cette artère, qui s'est révélée être une APPT, communiquait avec l'artère basilaire. Elle a fait l'objet d'une observation attentive, et les médecins ont établi qu'elle n'était pas responsable de la névralgie puisqu'elle ne comprimait pas le nerf à l'observation chirurgicale. Les médecins n'ont procédé à aucune intervention supplémentaire entre l'APPT et le nerf trijumeau. Les symptômes de la patiente se sont résorbés considérablement après l'opération, et l'évolution postopératoire a été sans histoire. La tomodensitométrie tridimensionnelle postopératoire a dévoilé l'APPT. Selon les observations découlant du présent cas, la transposition de l'artère atteinte décomprime la zone d'entrée de la racine et contribue à déterminer si l'APPT touche le nerf trijumeau.
$\mathrm{T}$ rigeminal neuralgia, also known as tic douloureux, is paroxysmal lancinating pain lasting a few seconds after being triggered by sensory stimuli such as speaking, chewing, washing the face, brushing the teeth or even a breeze on the face. The pathogenesis may be due to vascular compression of the trigeminal nerve at the root entry zone, posterior fossa tumour and multiple sclerosis $(1,2)$. Other vessels, including the anterior inferior cerebellar artery and the vertebrobasilar trunk or regional veins, have also been identified as offending vessels. Medical treatment with carbamazepine or gabapentin is highly successful initially, but many patients become refractory over time and require surgical therapy. The other therapies include alternative manipulation, such as gamma knife and glycerol treatment, as well as percutaneous trigeminal rhizotomy and radiofrequency rhizotomy. Decompression of the root entry zone (REZ) of the trigeminal nerve may be essential for improving the neuralgia.

A persistent primitive trigeminal artery (PPTA) is the most common persistent carotid-basilar artery anastomosis.

A PPTA is seen in $0.1 \%$ to $0.2 \%$ of angiograms (3). Occasionally, the posterior communicating artery may be hypoplastic and the PPTA may provide significant blood supply to the distribution of the distal basilar artery, the posterior cerebral artery and the superior cerebellar artery (SCA). A PPTA may be associated with vascular anomalies such as aneurysms or arteriovenous malformations (AVMs). It may also be associated with trigeminal neuralgia (3-9).

There are two types of PPTA: one courses medially to the basilar artery as shown in the present case, and the other, called a PPTA variant, courses laterally and directly into the cerebellar cortical artery (3-7). The first type of PPTA does not tend to compress the REZ of the trigeminal nerve $(6,7)$. The PPTA variant supplies the cerebellum directly without a basilar artery anastomosis (8). It is extremely rare that a PPTA or a PPTA variant compresses the trigeminal nerve. According to previous reports, these vessels were observed in only $0.2 \%$ to $0.6 \%$ of patients with trigeminal neuralgia (3-5). Some PPTAs are likely to compress the REZ, causing trigeminal neuralgia.

A case of trigeminal neuralgia caused by the SCA associated with a PPTA is presented. The SCA was completely transposed away from the trigeminal nerve by microvascular decompression. During surgery, it was evident that the PPTA itself did not compress the

${ }^{1}$ Department of Neurosurgery, Jikei University School of Medicine, Kashiwa Hospital, Kashiwa, Chiba; ${ }^{2}$ Department of Neurosurgery, Jikei University School of Medicine, Minato-ku, Tokyo, Japan

Correspondence and reprints: Dr Toshihide Tanaka, Department of Neurosurgery, Jikei University School of Medicine, Kashiwa Hospital, 163-1 Kashiwa-shita, Kashiwa, Chiba 277-8567, Japan. Telephone 81-4-7164-1111, fax 81-4-7163-3488, e-mail ttanaka@jikei.ac.jp 


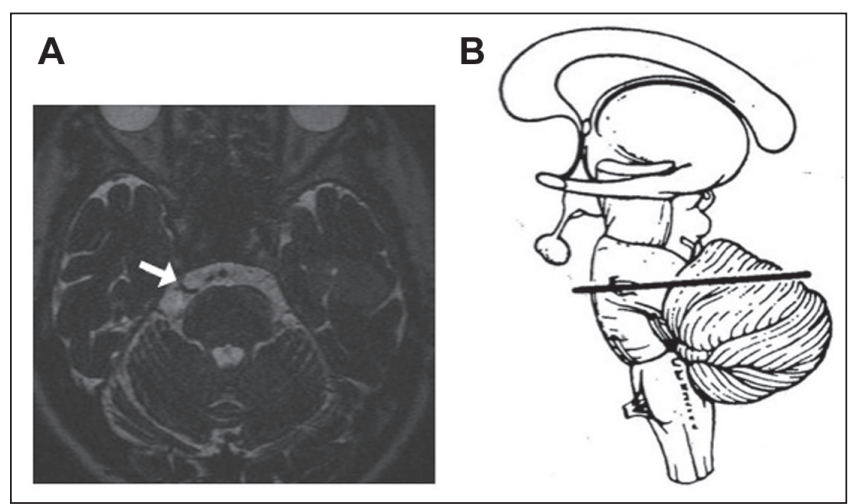

Figure 1) A Preoperative axial constructive interference in steady state image demonstrating flow void signals (arrow) attached to the right trigeminal nerve. B Schema of the brain stem. The transverse section revealed the axial image at the level of the root entry zone of the trigeminal nerve

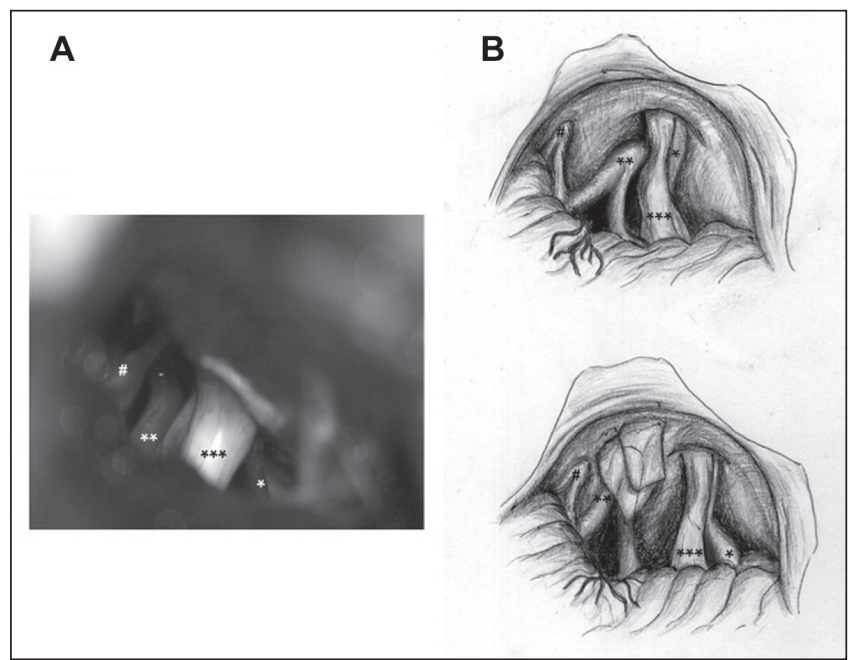

Figure 2) Photograph (A) and illustrations (B) demonstrating the microsurgical findings. The superior cerebellar artery (SCA) is seen at the ventrorostral side of the trigeminal nerve. A persistent primitive trigeminal artery (PPTA) is seen behind the same nerve (upper). Complete transposition of the SCA achieved decompression of the trigeminal nerve, and the PPTA is seen behind the trigeminal nerve, not compressing the nerve (lower). *PPTA; **SCA; ***Trigeminal nerve; \#Petrosal vein

trigeminal nerve. The transposition technique for microvascular decompression may be quite useful to determine whether the PPTA is the offending vessel.

\section{CASE PRESENTATION}

A 62-year-old woman, who presented with right orbital pain, was admitted to the hospital. The lancinating pain was stimulated by exercise, cold and light touch over the face. She had been treated with medication that included carbamazepine $(400 \mathrm{mg} /$ day $)$ for approximately three months. Neurological findings revealed no remarkable deficits. Brain magnetic resonance imaging demonstrated a flow void signal that was black on all images because flowing blood attached to the right trigeminal nerve (Figure 1). However, her neuralgia did not improve; rather, it gradually deteriorated and spread in the maxillary division. She agreed to surgical treatment and accepted the morbidity and mortality risks associated with it. She underwent right lateral suboccipital craniotomy. The dura was incised and turned over to each transverse and sigmoid sinus. The great horizontal fissure of the
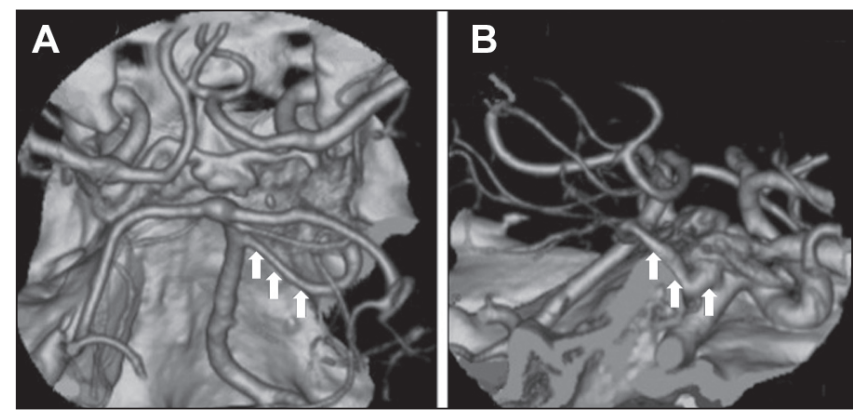

Figure 3) Postoperative three-dimensional computed tomography angiography showing the persistent primitive trigeminal artery (PPTA) penetrating Meckel's cave (arrows). The PPTA connects the basilar artery (A) and the carotid artery (B)

cerebellar hemisphere was dissected to open an adequate working space. The arachnoid membrane between the petrosal vein and the trigeminal nerve was carefully dissected. The cerebellar hemisphere was slowly retracted following aspiration of cerebrospinal fluid. The impression caused by the SCA was seen on the anteromedial surface of the trigeminal nerve without requiring the use of a spatula (Figures 2A and $2 \mathrm{~B}$ ). The SCA was transposed to the ventrorostral side from the trigeminal nerve and fixed toward the dura on the petrosal bone with Gelfoam (Pfizer Inc, USA) soaked in fibrin glue to achieve decompression. Subsequently, an abnormal vessel running toward Meckel's cave was found along the trigeminal nerve. This vessel originated directly from the basilar artery. At that time, the vessel was identified as a PPTA that did not compress the trigeminal nerve. Soon after the operation, the patient's symptoms improved dramatically and the pain disappeared completely the next day without sequelae. Her postoperative course was uneventful. The patient was discharged 10 days after surgery without neurological deficits, and she remains pain free without medication 14 months after the operation. A postoperative threedimensional computed tomography angiogram (3D-CTA) clearly demonstrated the PPTA (Figure 3).

\section{DISCUSSION}

A PPTA is an infrequent, anomalous vessel; trigeminal neuralgia associated with this vessel is uncommon (9-12). The incidence of trigeminal neuralgia caused by PPTA has been previously reported to range from $0.1 \%$ to $2.2 \%(4,6,7,9,10)$. It is known that PPTA is found with various vascular anomalies on radiological examinations including agenesis of the internal carotid artery, AVM and aneurysms, and trigeminal neuralgia $(10,12,13)$. Variant PPTA courses laterally to the cerebellar hemisphere directly without connection between the internal carotid artery and the basilar artery (3-7). Because of this structure, variant PPTA tends to compress the trigeminal nerve $(6,7)$. The present case did not have the variant type, and the offending artery was the SCA alone. The REZ of the trigeminal nerve is rarely compressed by nonvariant PPTA because the PPTA runs medially after emerging from Meckel's cave and entering the trunk of the basilar artery $(6,7)$. Therefore, transposition of the SCA alone was considered to be sufficient and effective for pain relief in the present case.

Axial constructive interference in steady state imaging provides useful information about the anatomical structure around the cranial nerves (9). In the present case, preoperative magnetic resonance images showed no aneurysm or AVM; however, PPTA could not be detected by preoperative constructive interference in steady state imaging (this vessel was found unexpectedly during surgery). To identify this anomalous artery preoperatively, magnetic resonance angiography might be useful (10). Magnetic resonance angiography itself does not provide sufficient information about precise anatomical structures around the skull base and the vessel. In particular, it is difficult to determine the route that the anomalous vessel takes between the internal carotid artery and the posterior fossa. On the other hand, 3D-CTA can provide more detailed 
information about the route in the skull base of this anomaly (14). It is known that there are several routes for the PPTA as it penetrates the skull, such as Meckel's cave, with the trigeminal root and the dural foramen at the dorsum sellae $(3,4)$.

We prefer the transposition technique with Gelfoam soaked in fibrin glue instead of interposition. In microvascular decompression, an adequate working space between the offending artery and the REZ of the trigeminal nerve, as if operating in a shallow basin, is essential. The arachnoid membrane along the trigeminal nerve should be carefully dissected to confirm the route of the offending artery. As Shigeno et al (15) described, the cerebellar hemisphere was carefully and slowly retracted without a spatula throughout the procedure to avoid excessive stress toward the cranial nerves and brain stem. Complete

\section{REFERENCES}

1. Peter J. Neurovascular compression in cranial nerve and systemic disease. Ann Surg 1980;192:518-4.

2. Kempe LG, Smith DR. Trigeminal neuralgia, facial spasm, intermedius and glossopharyngeal neuralgia with persistent carotid basilar anastomosis. J Neurosurg 1969;31:445-51.

3. Morita A, Fukushima T, Miyazaki S, Shimizu T, Atuchi M. Tic douloureux caused by primitive trigeminal artery or its variant. J Neurosurg 1989;70:415-9.

4. Tamura Y, Shimano H, Kuroiwa T, Yoshihito M. Trigeminal neuralgia associated with a primitive trigeminal artery variant: Case report. Neurosurgery 2003;52:1217-20.

5. Temizoz O, Genchellac H, Unlu E, Cagli B, Ozdemir H, Demir MK. Digital subtraction angiography of a persistent trigeminal artery variant. Diagn Interv Radiol 2010;16:245-7.

6. Tokimura H, Atsuchi M, Kawasaki T, et al. Trigeminal neuralgia associated with a primitive trigeminal artery: Report of two cases. No Shinkei Geka 1990;18:209-13.

7. Yamada Y, Kondo A, Tanabe H. Trigeminal neuralgia associated with an anomalous artery originating from the persistent primitive trigeminal artery - case report. Neurol Med Chir [Tokyo] 2006;46:194-7.

8. Pasco A, Papon X, Bracard S, Tanguy JY, Terminassian A, Mercier P. Persistent carotid-vertebrobasilar anastomoses: How and why differentiating them? J Neuroradiol 2004;31:391-6. transposition that secured free space between the offending artery and the REZ was accompanied by introducing Gelfoam soaked in fibrin glue around the artery and compressing it to the petrous dura. In the present case, it was possible to clearly identify the PPTA that did not compress the nerve. The SCA, as the offending artery, was transposed from the trigeminal nerve to achieve decompression.

To predict trigeminal neuralgia associated with an anomalous variant artery, preoperative angiography or 3D-CTA would be useful, but careful observation of intraoperative findings is important to decide whether these variant arteries cause trigeminal neuralgia. If an abnormal carotid vertebrobasilar anastomosis is noticed, a delicate manoeuvre, as described above, is necessary to prevent injury of these vessels.

9. Bondt BJ, Stokroos R, Cassleman J. Persistent trigeminal artery associated with trigeminal neuralgia: Hypothesis of neurovascular compression. Neuroradiology 2007;49:23-6.

10. Pereira LP, Nepomuceno LAM, Coimbra PP, Net SRO, Natal MRC. Persistent trigeminal artery: Angio-tomography and angio-magnetic resonance finding. Arq Neuropsiquiatr 2009;67:882-5.

11. Samra K, Scoville WB, Yaghmai M. Anastomosis of carotid and basilar arteries: Persistent primitive trigeminal artery and Hypoglossal artery: Report of two cases. J Neurosurg 1969;30:622-5.

12 Wakai S, Ueda Y, Nagai M. Cerebrovascular anomalies associated with primitive trigeminal artery: Report of three cases. Neurol Med Chir [Tokyo] 1987;27:633-6.

13. Fukuda M, Kameyama S, Takahashi H, Tanaka R. Trigeminal neuralgia caused by the vertebral artery associated with primitive trigeminal artery and agenesis of the internal carotid artery: Case report. Neurol Med Chir [Tokyo] 1998;38:367-70.

14. Suzuki Y, Kunii N, Matsumoto K. Persistent primitive trigeminal artery imaged by three-dimensional computed tomography angiography: Two case reports. Neurol Med Chir [Tokyo] 1999;39:748-51.

15. Shigeno T, Kumai J, Horikawa $H$, et al. Transposition technique of microvascular decompression for hemifacial spasm. No Shinkei Geka 2009;37:35-42. 


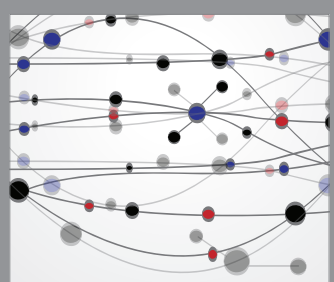

The Scientific World Journal
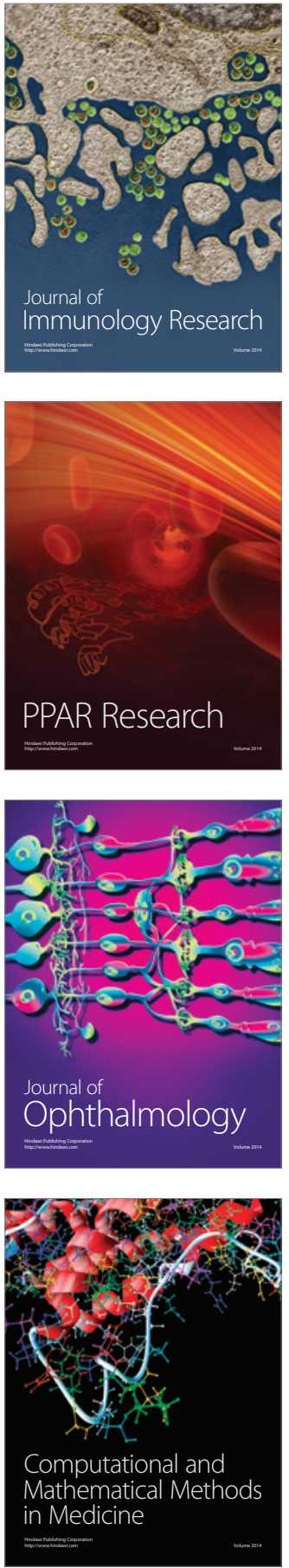

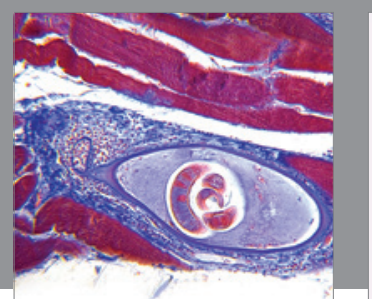

Gastroenterology Research and Practice

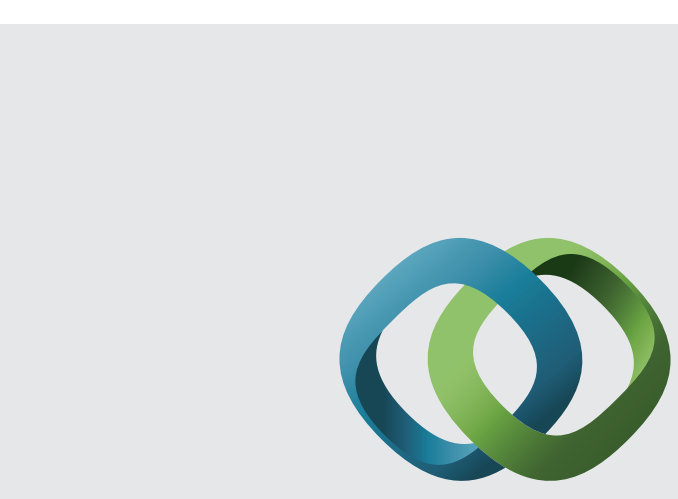

\section{Hindawi}

Submit your manuscripts at

http://www.hindawi.com
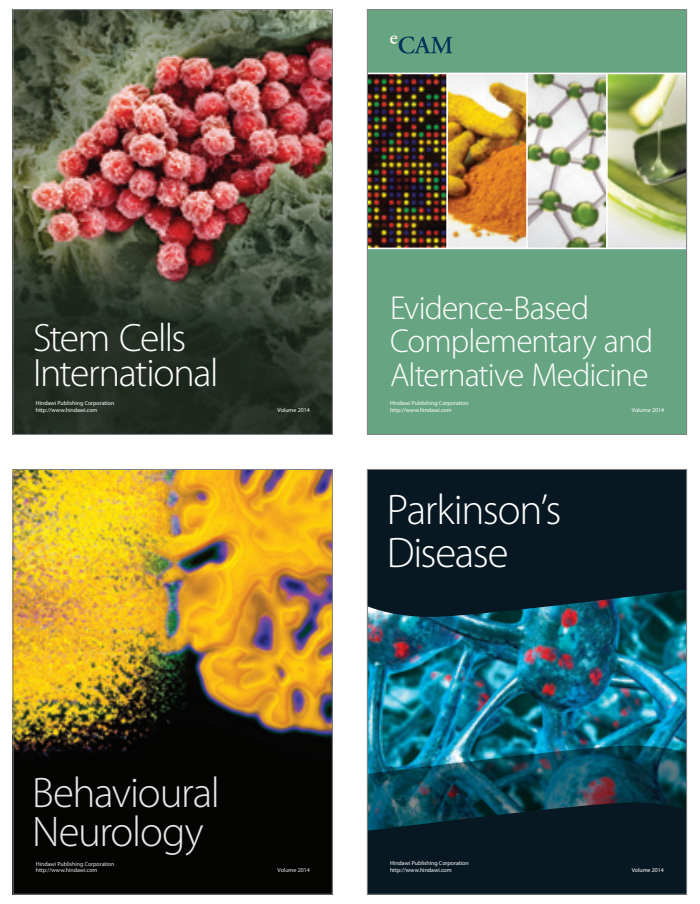
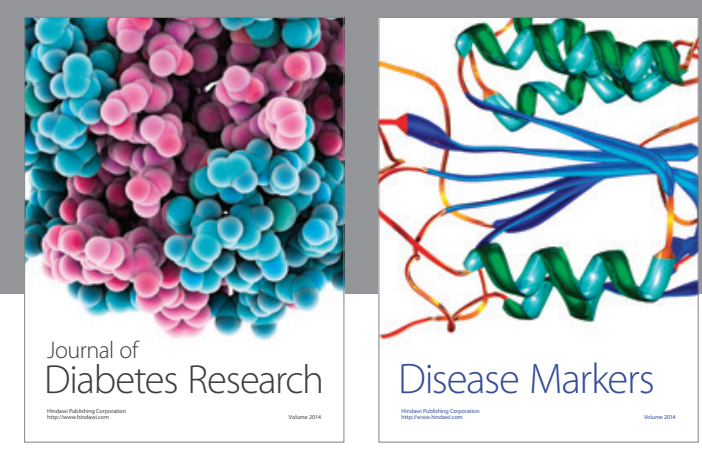

Disease Markers
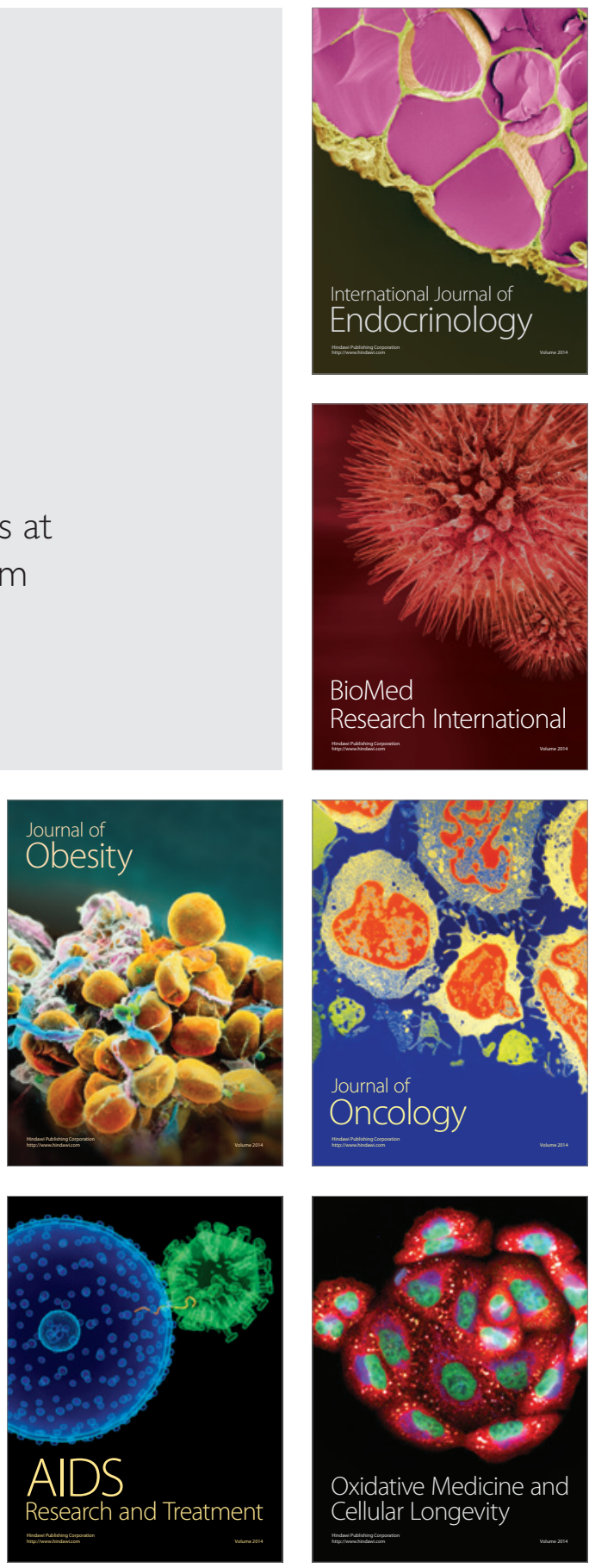